\title{
Restocking Herbivorous Fish Populations As a Social-Ecological Restoration Tool in Coral Reefs
}

\author{
Avigdor Abelson ${ }^{1 *}$, Uri Obolski ${ }^{2}$, Patrick Regoniel ${ }^{3}$ and Lilach Hadany ${ }^{2}$ \\ ${ }^{1}$ Department of Zoology, Tel-Aviv University, Tel-Aviv, Israel, ${ }^{2}$ Department of Molecular Biology and Ecology of Plants, Tel-Aviv \\ University, Tel-Aviv, Israel, ${ }^{3}$ Department of Biological and Physical Sciences, Palawan State University, Puerto Princesa, \\ Philippines
}

OPEN ACCESS

Edited by:

Christian Wild

University of Bremen, Germany

Reviewed by:

Andrew Chin

James Cook University, Australia Sebastian Christoph Alexander Ferse,

Leibniz Center for Tropical Marine Ecology, Germany Jan-Claas Dajka,

University of Bremen, Germany

*Correspondence: Avigdor Abelson avigdor@tauex.tau.ac.il

Specialty section:

This article was submitted to

Coral Reef Research

a section of the journal Frontiers in Marine Science

Received: 24 March 2016 Accepted: 25 July 2016 Published: 05 August 2016

Citation: Abelson A, Obolski U, Regoniel P and Hadany L (2016) Restocking Herbivorous Fish Populations As a Social-Ecological Restoration Tool in Coral Reefs. Front. Mar. Sci. 3:138. doi: 10.3389/fmars.2016.00138
The degradation of the world's coral reefs has aroused growing interest in ecological restoration as a countermeasure, which is widely criticized, mainly due to cost-effectiveness concerns. Here, we propose the restocking of herbivorous fish as a restoration tool, based on supply of young fish to degraded reefs, with the aims of: (1) Buildup of a critical fish biomass for basic ecosystem functions (e.g., grazing); (2) Increased fishing yields, which can sustain coastal communities, and consequently; (3) Reduced reef destruction and better local compliance with fishery policies. We present the rationale of the restocking approach as both a reef restoration and a fishery management tool, and examine its pros and cons. This approach requires, however, further social-ecological and aquaculture research in order to support the critical stages of its implementation.

Keywords: coral reefs, social-ecological restoration, fish restocking, biomanipulation, ecosystem management

\section{BACKGROUND}

\section{Coral Reef Degradation and Protection}

Coral reefs are declining worldwide due to the growing impact of stressors (such as overfishing, habitat destruction, pollution, and climate change), which threaten their biodiversity, ecological functions, and ecosystem services (e.g., Carpenter et al., 2008; Burke et al., 2011). The main management approach to counteracting coral reef decline is designation of marine protected areas (MPAs; e.g., Lester et al., 2009; Edgar et al., 2014) to reduce human endogenous (within-site) impacts, most notably over-fishing and habitat destruction. Well-managed and enforced coral-reef MPAs can enhance recovery following wide-scale natural disturbances, such as coral bleaching (Mumby and Harborne, 2010; De'ath et al., 2012; Gilmour et al., 2013). Moreover, MPAs may also benefit adjacent non-protected areas through the "spillover" of adult fish, or the export of larvae (e.g., Gaines et al., 2010; Russ and Alcala, 2011).

\section{MPA Limitations}

There is a growing body of literature showing that MPAs do not achieve all the expected conservation goals, such as reef community resistance to disturbances (Côté and Darling, 2010), or protection against exogenous stressors (Hilborn, 2015). Furthermore, in those cases in which MPAs are likely to fulfill the task of maintaining ecosystem health, or the recovery of degraded reefs (Abelson et al., 2016a), there are concerns regarding the socio-economic needs of local users, which in turn raise questions about the adequacy of MPAs as an ultimate solution (e.g., Christie, 2004; McClanahan et al., 2006). In this sense, many coral-reef MPAs are planned and evaluated by their ecological goals, while not meeting key social goals (e.g., Christie, 2004). Consequently, 
implementation of highly restricted MPAs and marine reserves may be challenging and prone to failure in areas where local communities greatly depend on reef ecosystem services (e.g., MacNeil et al., 2015). Furthermore, even in cases where MPAs can potentially contribute to remediating the reef, the time required for recovery may take many years or even decades (Carpenter et al., 2008; Blackwood et al., 2012; MacNeil et al., 2015). During this time, local communities are likely to suffer from an impaired livelihood under strict restrictions of "no-take" MPAs (i.e., marine reserves). Strict protection by MPAs may, therefore, be a problematic remedial solution if the basic requirements of the local communities that rely on the reefs' ecosystem services are not taken into account.

On the other hand, allowing unrestricted fishing activities is not a viable alternative as it may lead to a positive feedback, in which destructive fishing practices (e.g., cyanide and dynamite fishing) become more common as fish populations are depleted (e.g., McManus, 1997; White et al., 2000; Burke et al., 2011; Figure 1). A plausible outcome of this positive feedback is an accelerated decline of reefs to a point where basic ecosystem services are at risk (e.g., White et al., 2000), which may lead to "poverty traps" (Cinner et al., 2009, 2013). Such degradation cascades can already be witnessed in wide reef areas in South-East Asia (e.g., Burke et al., 2011; Hughes et al., 2013). Alternatively, in areas where fishing yields are still reasonable, fishing may remove herbivorous fish (e.g., Bejarano et al., 2013; MacNeil et al., 2015), potentially reducing ecological functions, altering trophic structures, and thereby threatening the reef's ecosystem integrity and resilience (Folke et al., 2004; Rogers et al., 2015), which may lead to "ecological vulnerability" and socio-economic traps (Cinner, 2011; Cinner et al., 2013).

\section{Fishery Management Limitations}

To address the problem of fishing "business as usual" in areas where MPAs may be socially challenging or infeasible, a moderate fishery management approach has been proposed that can allow a certain exploitation while still maintaining essential ecosystem services (e.g., Siar et al., 1992; Bartlett et al., 2009; MacNeil et al., 2015). It is claimed that some forms of fishery management can enhance essential reef ecosystem functions and resilience, while also enabling the continuous consumption of reef fish necessary for the livelihood of local fishing communities (e.g., MacNeil et al., 2015). In reef areas where MPAs cannot be implemented, such fishery management tools may encounter less resistance and enhance collaboration among the different stakeholders and, therefore, can better achieve the goals of reef recovery without impairing the local community's livelihood.

Fishery management, however, may have some limitations as a countermeasure of reef degradation. These are mainly related to the relatively long time it takes to return the reef and the fish community to a state in which they enable essential ecosystem functions (e.g., Blackwood et al., 2012). Moreover, many reef sites are characterized by highly depleted fish communities (e.g., Burke et al., 2011; MacNeil et al., 2015), with fish biomass below $0.25 \mathrm{~B}_{0}$ (where $\mathrm{B}_{0}$ is reef fish biomass in the absence of fishing; see McClanahan et al., 2011; MacNeil et al., 2015), as a threshold below which multiple negative ecosystem effects of overfishing have been shown (MacNeil et al., 2015).

The recovery of such heavily depleted reefs is expected to take decades (Blackwood et al., 2012; MacNeil et al., 2015), and may impose some challenges and risks. First, the basic ecosystem functions and the structural complexity (estimated by measuring "rugosity" as a proxy for complexity; Alvarez-Filip et al., 2009) of the reef may continue to deteriorate due to the "detrimental cascading effects related to the removal of predators and herbivores" (Newton et al., 2007)_cascades which can lead to a further decline in the reef's fish community and fishery yields (Graham et al., 2006). Second, low resilience (as may be indicated by a low functional diversity of fish; Cheal et al., 2010), combined with a long recovery time of the reef fish community, exposes the reef to an increased risk of phase shift into a macroalgaedominated reef, following mass coral mortality events. Disturbed reefs are prone to experience positive feedbacks, which can lead to stable states of low coral coverage that exhibit hysteresis (e.g., Mumby et al., 2007): A situation in which much higher values of the critical parameters (e.g., grazing rates) are needed for the degraded ecosystem to shift back to its original state, than the threshold values that caused the phase shift in the first place (Suding et al., 2004). Therefore, removing the stress (e.g., fishing) from a system does not necessarily ensure a return to a coral-dominated reef. Third, slow reef recovery implies reduced fishing yields for a long period, the outcome of which is a poor livelihood for the local communities. The long recovery time and the resulting poor livelihood are expected to pose socioeconomic challenges, which may prevent compliance by the local stakeholders and consequently impede the establishment of suitable conditions for reef recovery.

The projected long recovery time, the reduced trophic level, and the socio-economic challenges related to the existing management approaches highlight the need for additional tools that can help to address, within a relatively short time, both the ecological and the socio-economic challenges; that is, to promote recovery of the reef ecosystem while sustaining the livelihood of its reliant coastal populations (e.g., Abelson et al., 2016b).

\section{CORAL-REEF RESTORATION AND FISH POPULATION RESTOCKING}

One suggested countermeasure to the fast degradation of coral reefs is that of ecological restoration intervention, which at present consists mainly of coral transplantation ("reef gardening"; e.g., Edwards, 2010; Rinkevich, 2014). This restoration solution has been widely criticized for its high costs (and therefore scalability problems; e.g., Adger et al., 2005; Mumby and Steneck, 2008), and for treating the symptoms rather than the causes of degradation (Stone, 2007; Mumby and Steneck, 2008). These drawbacks may be attributable to the limitations of available tools and practices (Abelson et al., 2016b), scarce and poorly-directed funding, and the common goal of restoration projects to achieve an "item-based success" (i.e., survival of planted transplants, seedlings, or spats; sensu Bayraktarov et al., 2016). 


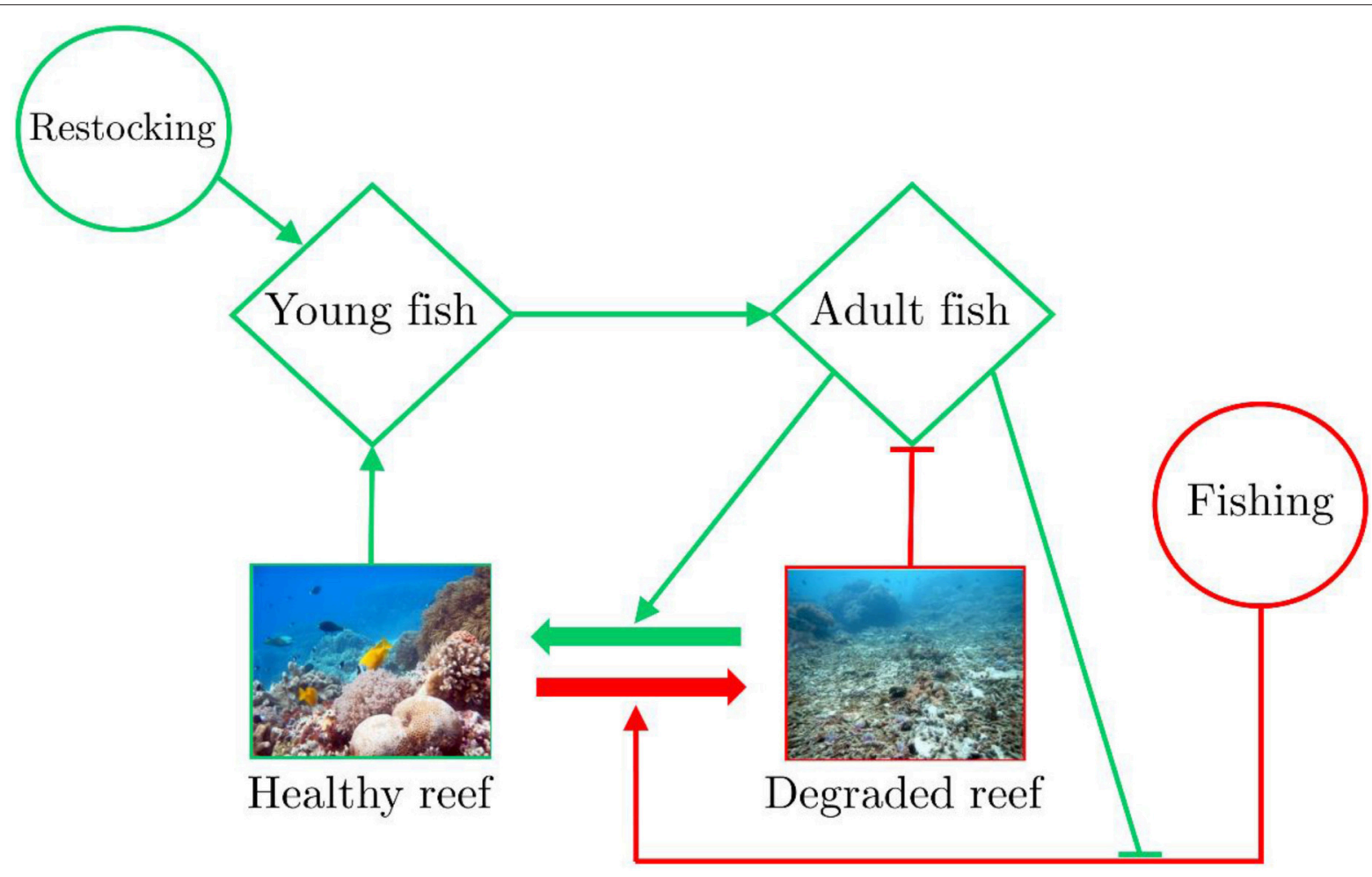

FIGURE 1 | Flow chart of human-reef processes influencing a coral reef's state. Beneficial processes are marked with green arrows whereas detrimental processes are marked with red arrows. Increasing the number of fish may help to reduce algal coverage, which otherwise inhibits coral reef recovery. Healthy reefs, in turn, provide a suitable habitat and help fish to proliferate. This creates a positive feedback loop beneficial to reef recovery. In contrast, fishing reduces the number of fish in the reef and can also harm the reef directly through destructive fishing; degraded reefs reduce the fish population by removing suitable fish habitats (red flat-head arrow). When the number of adult fish increases, as a result of restocking, fishing has a lower detrimental effect on the fish population and fishermen are less likely to resort to destructive fishing (green flat-head arrow).

Here, we propose "fish restocking" practices as a coralreef restoration tool, as well as a fishery management aid in degraded reefs. The fish population restocking should be applied in addition to forms of protection (e.g., MPAs) or fishery management. It can also be applied in addition to other restoration interventions, where applicable (e.g., Abelson et al., 2016b), and requires the compliance and active support of local stakeholders (Ferse et al., 2010). The restocking of herbivorous fish populations could serve as a potential solution to fish depletion and its adverse consequences in localities of high dependency of the coastal communities on the reef as a source of livelihood. Fish restocking and "stock enhancement" are used as generic terms referring to all forms of hatchery-based fishery enhancement tools in aquatic and marine ecosystems (e.g., Blankenship and Leber, 1995; Lorenzen et al., 2013). The proposed approach is based on the re-introduction of cultured fish (i.e., reproduced and reared to young stages by aquaculture methods) into the reef as a restoration tool that may be able to address both the ecological and the social challenges of degraded reefs and depleted reef fish populations.

Fish restocking, or stock enhancement, can have several effects (Figure 1): (1) Shortening the recovery time of depleted fish populations in the target reef. (2) Supporting fishery by increasing fishing yields. (3) Enhancing the ecosystem functions essential for reef recovery (notably the removal of benthic algae-macroalgae and/or algal turfs) and, therefore accelerating recovery and "bouncing" the reefs back to their coral-dominated state. (4) Enhancing the resilience of the target reefs to future perturbations.

\section{Target Reefs and Applicable Conditions}

Fish population restocking is not suggested as an ultimate solution for all degraded reefs. It could, however, serve as an additional restoration tool in areas in which MPAs, or existing fishery management, are not likely to be effective as sole measures, due to the social-political circumstances or the progressively-depleted reef state. Moreover, fish restocking is not expected to fulfill its goal in conditions of low structural complexity, low coral recruitment, and/or high macroalgal cover reefs without artificial complexity enhancement, coral transplantation, and algal eradication, respectively (see Table 1; Abelson, 2006; Rogers et al., 2015; Abelson et al., 2016b).

One category of high-priority target reefs for restocking-based restoration is that of the degraded reefs that have undergone a phase shift from a coral-dominated state to domination by 
TABLE 1 | Categories of degraded states of coral reefs, their main live cover, and potential restoration tools.

\begin{tabular}{|c|c|c|c|}
\hline Degradation category & Main live cover & Potential restoration tools & $\begin{array}{l}\text { Estimated implementation difficulty } \\
\text { and cost (I-lowest to } \mathrm{V} \text {-highest) }\end{array}$ \\
\hline Type I Seaweed reef & Macroalgae & $\mathrm{AE} ; \mathrm{FR} ; \mathrm{CT}^{\star} ; \mathrm{AC}^{\star}$ & IV \\
\hline Type II Turf reef & Algal turfs & $\mathrm{AC}^{\star} ; \mathrm{FR} ; \mathrm{CT}^{*}$ & III \\
\hline Type III Depauperate reef & Reef-building corals & FR & I \\
\hline Type IV Coralline reef & Exposed rock/Coralline algae (CCA) & $\mathrm{AC}^{\star} ; \mathrm{FR} ; \mathrm{CT}$ & $\|$ \\
\hline Type V Ruined reef & Rubble/debris (Structurally destroyed reef) & SS; AC; CT; FR & V \\
\hline
\end{tabular}

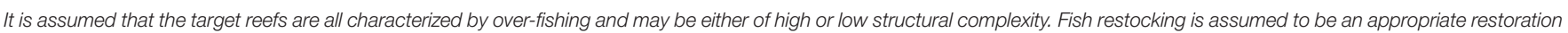

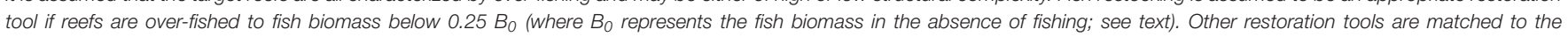
cover characteristics and structural complexity level. AE, Algal Eradication; CT, Coral transplantation; FR, Fish restocking; AC, Artificial complexity; SS, Substrate stabilization; AC*, Implementation of artificial complexity assuming low structural complexity; CT*, Coral transplantation assuming low coral larval supply, or low survival during early stages.

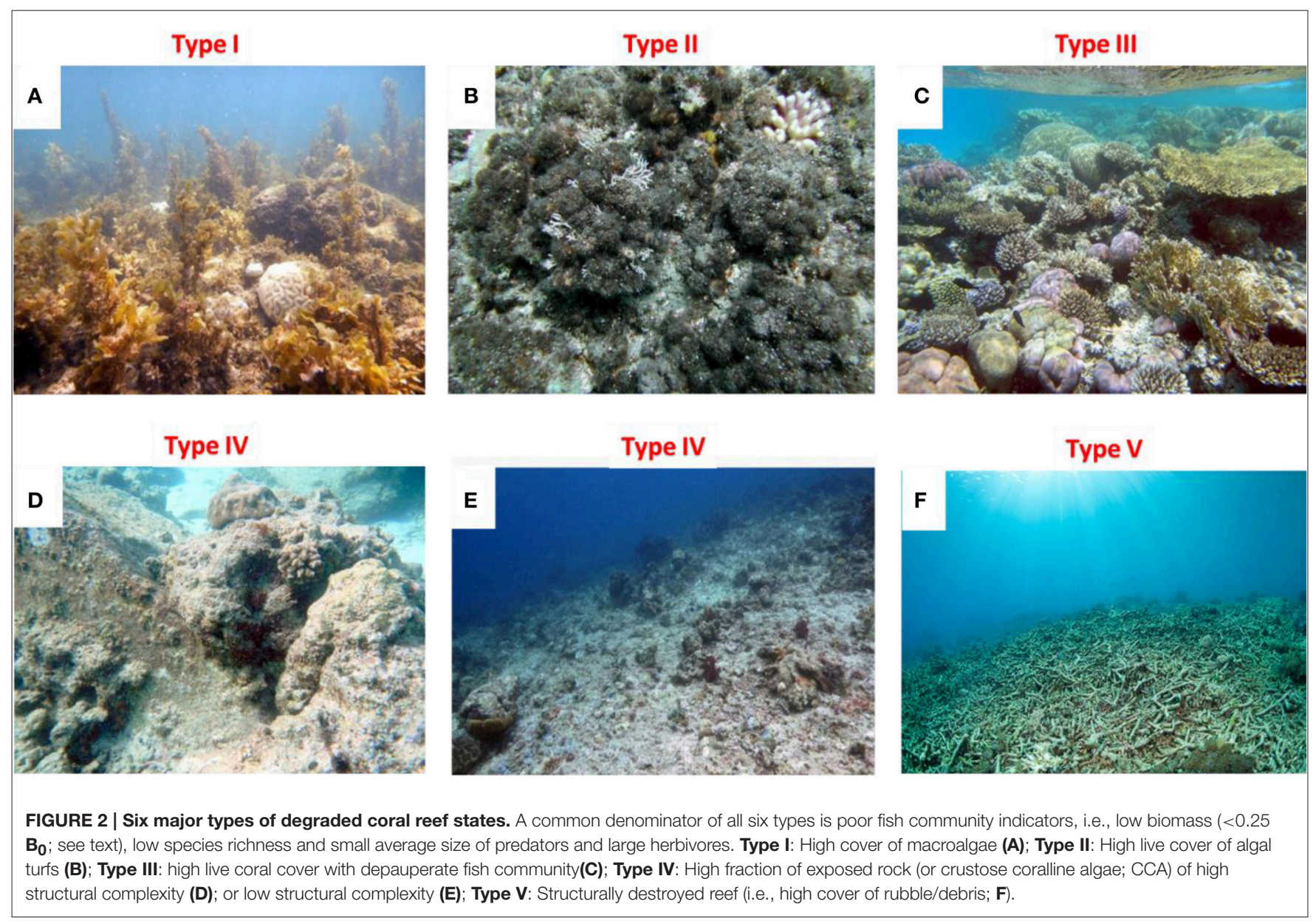

benthic algae (e.g., Bellwood et al., 2006; Bahartan et al., 2010), either macroalgae (Type I; Table 1; Figure 2A), or algal turfs (Type II; Table 1; Figure 2B), mainly due to over-fishing. Reefs dominated by macroalgae or algal turfs may suffer from limited recruitment, due to either adverse effects on corals and fish recruits, or a negative preference of potential recruits (Kuffner et al., 2006; Birrell et al., 2008; Dixson et al., 2014; Kelly et al., 2014). In such cases, the common reef restoration tool of coral transplantation is not likely to be effective in counteracting the potential damaging effects of algae on adult corals (Birrell et al., 2008; Dixson et al., 2014). On the other hand, intensive grazing and browsing activities following augmented populations of herbivorous fish may help in re-shifting the reef back to a coral dominated state through the removal of algae. An example of such rapid removal of algae was demonstrated in exclosures (exclusion experiments) in which fish herbivory reduced about half of a 3-year old macroalgal cover within 5 days (Bellwood et al., 2006).

Another category of target reefs for fish restocking implementation comprises degraded reefs of Type III (Table 1; 
Figure 2C), where the coral live-cover is high, but the reefs suffer from severely depleted fish communities, notably of herbivorous fish. Type III reefs, despite their high coral cover, may be of low resilience and under high risk of deterioration if exposed to mass coral mortality following extensive disturbances, such as crown-of-thorn starfish outbreaks and mass bleaching (e.g., Folke et al., 2004). In such reefs, fish restocking can be applied as a "proactive measure" to augment reef resilience and the livelihood of local fishing communities.

A third category of candidate reefs for fish restocking includes degraded reefs of Type IV (Table 1; Figures 2D,E), which are reefs of low coral cover and a high fraction of exposed rock, or crustose coralline algae (CCA). As in Type III, fish restocking can be applied as a "proactive measure" to augment reef resilience and the livelihood of local fishing communities. However, prior to implementing the restocking, artificial complexity enhancement and coral transplantation interventions should be considered (Table 1) to enable adequate shelter for the restocked fish.

Degraded reefs of Type V, which are structurally destroyed (Table 1; Figure 2F), require substrate stabilization interventions, in addition to the other available restoration methods. At present, substrate stabilization interventions are not considered to be effective on large spatial scales (Fox and Caldwell, 2006). Moreover, the combined restoration projects of such destroyed reefs are expected to entail a high cost.

\section{Pros and Cons of Fish Restocking}

There are diverse technical, ecological, and socio-economic aspects that may impede the potential success of restocking interventions in coral reefs, the majority of which are also relevant to other restoration interventions. These include, among others: High-cost production expenses, insufficient funding, lack of compliance of local stakeholders, below-threshold survival rates of the restocked fish, fish movement out of the target site, non-restricted illegal fishing, inadequate aquaculture technologies of relevant species, and adverse effects of the restocked fish on the target reef community. Additionally, there are potential adverse effects of aquaculture practices on coastal ecosystems, related to food sources (mainly of carnivorous fish), eutrophication (by mass culture to adult size) and the culturing of non-indigenous species, or genotypes. The "fish restocking" concept refers to indigenous genotypes (i.e., local broodstocks) of herbivorous fish cultured to juvenile stages, thus minimizing the abovementioned adverse effects. Moreover, if "Integrated Multi-Trophic Aquaculture" (IMTA) is applied (e.g., Soto, 2009), it is expected to further reduce the environmental impact and enhance the income of local stakeholders via aquaculture as an alternative source of livelihood.

These potential impediments and drawbacks can be assessed in the early stages by means of pre-launch experiments and analyses, to evaluate the site-specific success chances and cost-benefit of the proposed fish-restocking projects. These prelaunch steps (see Section Proposed implementation steps of restoration by restocking) can help in determining whether the proposed approach of restocking is applicable, and where, which reef types, and under what socio-economic circumstances.
In contrast, there are several arguments that may support the feasibility of fish restocking when appropriately planned and applied. These include:

Economic feasibility. The results of a recent model-based study suggest that restocking may be a financially beneficial restoration tool (Obolski et al., 2016), due to the high economic value of coral-reef services (Costanza et al., 2014) and the potentially low cost of restocking (Lorenzen et al., 2013; Obolski et al., 2016). When compared with coral transplantation (which is currently the major restoration tool; Edwards, 2010; Rinkevich, 2014), fish restocking has significantly lower costs and carries potential socio-economic benefits to coastal communities. These advantages should incentivize its implementation, alongside other tools, or as a major intervention, if applicable (Obolski et al., 2016).

Fish restocking experience in aquatic and marine environments. Fish population restocking has been commonly used as a restoration, or biomanipulation, tool in the management of aquatic ecosystems, aimed at restoring water quality and vegetation characteristics (e.g., Cowx, 1999; Angeler, 2010). Furthermore, recent attempts of fish restocking have been carried out in coastal marine ecosystems, mainly as a fishery management tool of target commercial fish populations (Lindegren et al., 2010; Lorenzen et al., 2013). In coral reefs, however, to the best of our knowledge, there are no reports on fish restocking intervention attempts other than experimental stock enhancement with two species of rabbitfish (Siganus lineatus and Siganus fuscescens; Bowling, 2014).

Technical breeding (culture) feasibility. At present, most herbivorous reef-fish species are not cultured. However, there is some knowledge of breeding technologies of several herbivorous species (e.g., Hara et al., 1986; Estudillo et al., 1998), most of which have been reported in non-peer reviewed literature (e.g., Hirai et al., 2013; Ayson et al., 2014; Bowling, 2014). Based on the progress achieved in breeding technologies, in spite of poor funding, the possibility of acquiring additional knowledge seems feasible if adequate resources are allocated to reef-fish aquaculture. Moreover, there are diverse ongoing initiatives around the world that are examining the restocking of exploitable fish species either for human consumption, or as ornamental species (MASNA, 2016).

\section{Proposed Implementation Steps of Restoration by Restocking}

The fish restocking management tool should be viewed as part of a comprehensive coral-reef management approach, which includes protection and fishing regulations, and requires the compliance and support of the local communities for its success (Ferse et al., 2010). To maximize the chances of success and minimize risks, it is proposed to consider a series of steps that would allow assessing and implementing critical parameters:

1. The reef degradation state and the appropriateness of the restocking tool. The reef state should fit one of the relevant 
degradation types (Table 1; Figure 2). In degraded reefs of type III, the restocking tool can be considered as a sole restoration intervention. However, in most degradation types further interventions, such as algal eradication, artificial complexity enhancement, coral transplantation, and substrate stabilization, may be required (Table 1; e.g., Rogers et al., 2015; Abelson et al., 2016a). The costs of these interventions may raise, however, questions regarding the scalability and implementation circumstances of combined restoration interventions.

2. The target herbivorous species. In addition to general functional groups (i.e., based on trophic level), fish species should be categorized into grazers, scrapers, and browsers (Green and Bellwood, 2009); where "grazers" are species that feed on algal turfs, preventing the establishment and growth of macroalgae; "scrapers" feed on turfs but erode some component of the reef substratum, which clears areas for coral recruitment; and "browsers" graze on macroalgae (Green and Bellwood, 2009). Therefore, the latter (browsers), or generalist herbivore fishes (Bellwood et al., 2006; Green and Bellwood, 2009) may be the key species for the reversal of macroalgal-dominated reefs. Moreover, recent studies indicate that only a small subset of taxa may be necessary in order to remove dominant macroalgae once these become established (e.g., Vergés et al., 2012). For example, despite marked differences in the diversity, biomass, and community composition of resident herbivorous fishes of different reefs, Sargassum consumption was found to be dominated by only four species, with two species (i.e., Naso unicornis and Kyphosus vaigiensis) consistently emerging as dominant feeders of the macroalgae (Hoey and Bellwood, 2009; Vergés et al., 2012), where the target species seem to present regional and site-specific features. Thus, selecting an appropriate set of species is crucial for the success of the restocking intervention and has to be determined by pre-launch studies. Following the selection of candidate species, exploratory enclosure/exclosure experiments (e.g., Bellwood et al., 2006; Burkepile and Hay, 2011) should be conducted to examine the compatibility of the candidate herbivorous fish with the target reef. Factors to be considered should include, among others, the sitespecific survival of released fish, their actual functional role and efficiency, and their potential effects on the target reef community.

3. Capacity building and public awareness of local stakeholders prior to any "restocking project" implementation. This is an essential step to ensure the collaboration of the relevant communities, sound exploitation based on a compatible fishery management, and to avoid abuse of the new, enriched fishing conditions.

4. Technical knowledge of the relevant species' culture. Establishment of appropriate aquaculture systems, including hatchery, nursery, and grow-out systems to produce the fish stock, from eggs to released size/age. Since the "restocking" tool is applied to enhance depleted natural fish populations by releasing cultured fish into the wild, the brood-stock sources should be fish from local populations and, ideally, the brood populations should be large enough to ensure high variability and avoid the founder's effect and population bottlenecks (e.g., Champagnon et al., 2012).

5. Feasibility examination. The proposed approach should be compared with costs of conservation, different fishery management options, and other coral-reef restoration tools (e.g., coral transplantation) in order to evaluate the most effective approach-or combination of approaches-in terms of recovery time, scalability, and socio-economic benefits. There are diverse social and cost-related considerations that may determine the feasibility of any restocking program, based on its location, such as accessibility, available infrastructure, and local expertise. These aspects emphasize the importance of site-specific feasibility examination.

\section{CONCLUSIONS AND RECOMMENDATIONS}

- Reef-fish population restocking, if proven applicable, can open up a new direction for social-ecological restoration of degraded reefs. It can both accelerate recovery of degraded reefs as well as aid fishery management in areas where the reefs no longer support their reliant coastal communities.

- The restocking tool is not suggested as a solution for all reef degradation states, nor can it serve as an effective tool under all environmental and social conditions. There are reef states and circumstances which may require other coral-reef restoration tools as alternative or additional tools for fish restocking. In all cases, however, a prerequisite for success is the compliance and active support of local stakeholders.

- To explore the restocking approach as a feasible restoration tool a series of experiments, examinations, and analyses are required. These include the diverse technical, ecological, and socio-economic aspects that may impede the potential success of restocking interventions in coral reefs. These potential impediments should be identified and assessed in the early stages in order to determine whether the proposed approach of restocking is applicable.

- Future reef management plans should also consider allocating efforts to improving breeding and culture technologies of species valuable for reef recovery, in order to attain the goals of both reef recovery and the provision of alternative livelihoods.

The environmental and socio-economic requirements for a successful application of restocking emphasize the necessity of a multidisciplinary approach, involving collaboration among ecologists, aquaculture experts, social scientists and economists, as well as among stakeholders, academics, and decision-makers.

\section{AUTHOR CONTRIBUTIONS}

All authors listed, have made direct and intellectual contribution to the work, and approved it for publication.

\section{FUNDING}

This project was supported by the Israeli Science Foundation 1568/13 (LH) and by a fellowship from the Manna Program in Food Safety and Security (UO). 


\section{REFERENCES}

Abelson, A. (2006). Artificial reefs vs coral transplantation as restoration tools for mitigating coral reef deterioration: benefits, concerns, and proposed guidelines. Bull. Mar. Sci. 78, 151-159.

Abelson, A., Halpern, B. S., Reed, D. C., Orth, R. J., Kendrick, G. A., Beck, M. W., et al. (2016b). Upgrading marine ecosystem restoration using ecological-social concepts. BioScience 66, 156-163. doi: 10.1093/biosci/biv171

Abelson, A., Nelson, P. A., Edgar, G. J., Shashar, N., Reed, D. C., Belmaker, J., et al. (2016a). Expanding marine-protected areas to include degraded coral reefs. Conserv. Biol. doi: 10.1111/cobi.12722. [Epub ahead of print].

Adger, W. N., Hughes, T. P., Folke, C., Carpenter, S. R., and Rockstrom, J. (2005). Social-ecological resilience to coastal disasters. Science 306, 1306-1309. doi: $10.1126 /$ science. 1112122

Alvarez-Filip, L., Dulvy, N. K., Gill, J. A., Côté, I. M., and Watkinson, A. R. (2009). Flattening of Caribbean coral reefs: region-wide declines in architectural complexity. Proc. Roy. Soc. B Biol. Sci. 276, 3019-3025. doi: 10.1098/rspb.2009.0339

Angeler, D. (2010). "Biomanipulation: a useful tool for wetland rehabilitation," in Ecology of Threatened Semi-Arid Wetlands, eds S. Sánchez-Carrillo and D. G. Angeler (Dordrecht: Springer Science+Business Media), 215-228.

Ayson, F. G., Reyes, O. S., and de Jesus-Ayson, E. G. T. (2014). Seed Production of Rabbitfish Siganus guttatus. Iloilo: SEAFDEC.

Bahartan, K., Zibdah, M., Ahmed, Y., Israel, A., Brickner, I., and Abelson, A. (2010). Macroalgae in the coral reefs of Eilat (Gulf of Aqaba, Red Sea) as a possible indicator of reef degradation. Mar. Pollut. Bull. 60, 759-764. doi: 10.1016/j.marpolbul.2009.11.017

Bartlett, C. Y., Manua, C., Cinner, J., Sutton, S., Jimmy, R., South, R., et al. (2009). Comparison of outcomes of permanently closed and periodically harvested coral reef reserves. Conserv. Biol. 23, 1475-1484. doi: 10.1111/j.15231739.2009.01293.x

Bayraktarov, E., Saunders, M. I., Abdullah, S., Mills, M., Beher, J., Possingham, H. P., et al. (2016). The cost and feasibility of marine coastal restoration. Ecol. Appl. 26, 1055-1074. doi: 10.1890/15-1077

Bejarano, S., Golbuu, Y., Sapolu, T., and Mumby, P. J. (2013). Ecological risk and the exploitation of herbivorous reef fish across Micronesia. Mar. Ecol. Prog. Ser. 482, 197-215. doi: 10.3354/meps 10270

Bellwood, D. R., Hughes, T. P., and Hoey, A. S. (2006). Sleeping functional group drives coral-reef recovery. Curr. Biol. 16, 2434-2439. doi: 10.1016/j.cub.2006.10.030

Birrell, C. L., McCook, L. J., Willis, B. L., and Diaz-Pulido, G. A. (2008). Effects of benthic algae on the replenishment of corals and the implications for the resilience of coral reefs. Oceanogr. Mar. Biol. Annu. Rev. 46, 25-63. doi: 10.1201/9781420065756.ch2

Blackwood, J. C., Hastings, A., and Mumby, P. J. (2012). The effect of fishing on hysteresis in Caribbean coral reefs. Theor. Ecol. 5, 105-114. doi: 10.1201/9781420065756.ch2

Blankenship, H. L., and Leber, K. M. (1995). "A responsible approach to marine stock enhancement," in American Fisheries Society Symposium, Vol. 15 (Bethesda, MD), 167-175.

Bowling, T. (2014). Bumphead breakthrough: culturing the vulnerable king of the parrotfishes. Coral 11, 12-27.

Burke, L. M., Reytar, K., Spalding, M., and Perry, A. (2011). Reefs at Risk Revisited. Washington, DC: World Resources Institute.

Burkepile, D. E., and Hay, M. E. (2011). Feeding complementarity versus redundancy among herbivorous fishes on a Caribbean reef. Coral Reefs 30, 351-362. doi: 10.1007/s00338-011-0726-6

Carpenter, K. E., Abrar, M., Aeby, G., Aronson, R. B., Banks, S., Bruckner, A., et al. (2008). One-third of reef-building corals face elevated extinction risk from climate change and local impacts. Science 321, 560-563. doi: $10.1126 /$ science. 1159196

Champagnon, J., Elmberg, J., Guillemain, M., Gauthier-Clerc, M., and Lebreton, J. D. (2012). Conspecifics can be aliens too: a review of effects of restocking practices in vertebrates. J. Nat. Conserv. 20, 231-241. doi: 10.1016/j.jnc.2012.02.002

Cheal, A. J., MacNeil, M. A., Cripps, E., Emslie, M. J., Jonker, M., Schaffelke, B., et al. (2010). Coral-macroalgal phase shifts or reef resilience: links with diversity and functional roles of herbivorous fishes on the Great Barrier Reef. Coral Reefs 29, 1005-1015. doi: 10.1007/s00338-010-0661-y

Christie, P. (2004). "Marine protected areas as biological successes and social failures in Southeast Asia," in American Fisheries Society Symposium, Vol. 42 (Bethesda, MD), 155-164.

Cinner, J. E. (2011). Social-ecological traps in reef fisheries. Glob. Environ. Change 21, 835-839. doi: 10.1016/j.gloenvcha.2011.04.012

Cinner, J. E., Daw, T., and McClanahan, T. R. (2009). Socioeconomic factors that affect artisanal fishers' readiness to exit a declining fishery. Conserv. Biol. 23, 124-130. doi: 10.1111/j.1523-1739.2008.01041.x

Cinner, J. E., Huchery, C., Darling, E. S., Humphries, A. T., Graham, N. A., Hicks, C. C., et al. (2013). Evaluating social and ecological vulnerability of coral reef fisheries to climate change. PLoS ONE 8:e74321. doi: 10.1371/journal.pone.0074321

Costanza, R., de Groot, R., Sutton, P., van der Ploeg, S., Anderson, S. J., Kubiszewski, I., et al. (2014). Changes in the global value of ecosystem services. Glob. Environ. Change. 26, 152-158. doi: 10.1016/j.gloenvcha.2014.04.002

Côté, I. M., and Darling, E. S. (2010). Rethinking ecosystem resilience in the face of climate change. PLoS Biol. 8:e1000438. doi: 10.1371/journal.pbio.10 00438

Cowx, I. G. (1999). An appraisal of stocking strategies in the light of developing country constraints. Fish. Manag. Ecol. 6, 21-34. doi: 10.1046/j.13652400.1999.00139.x

De'ath, G., Fabricius, K. E., Sweatman, H., and Puotinen, M. (2012). The 27-year decline of coral cover on the Great Barrier Reef and its causes. Proc. Natl. Acad. Sci. U.S.A. 109, 17995-17999. doi: 10.1073/pnas.1208909109

Dixson, D. L., Abrego, D., and Hay, M. E. (2014). Chemically mediated behavior of recruiting corals and fishes: a tipping point that may limit reef recovery. Science 345, 892-897. doi: 10.1126/science. 1255057

Edgar, G. J., Stuart-Smith, R. D., Willis, T. J., Kininmonth, S., Baker, S. C., Banks, S., et al. (2014). Global conservation outcomes depend on marine protected areas with five key features. Nature 506, 216-220. doi: 10.1038/nature13022

Edwards, A. J. (2010). Reef Rehabilitation Manual. St. Lucia: The Coral Reef Targeted Research; Capacity Building for Management Program.

Estudillo, C. B., Duray, M. N., and Marasigan, E. T. (1998). Growth and survival of milkfish (Chanos chanos), seabass (Lates calcarifer) and rabbitfish (Siganus guttatus) larvae reared at the same density in different sized tanks. Isr. J. Aquaculture Bamidgeh 50, 20-24.

Ferse, S. C. A., Máñez Costa, M., Schwerdtner Máñez, K., Adhuri, D. S., and Glaser, M. (2010). Allies, not aliens: increasing the role of local communities in marine protected area implementation. Environ. Conserv. 37, 23-34. doi: $10.1017 /$ S0376892910000172

Folke, C., Carpenter, S., Walker, B., Scheffer, M., Elmqvist, T., Gunderson, L., et al. (2004). Regime shifts, resilience, and biodiversity in ecosystem management. Annu. Rev. Ecol. Evol. Syst. 35, 557-581. doi: 10.1146/annurev. ecolsys.35.021103.105711

Fox, H. E., and Caldwell, R. L. (2006). Recovery from blast fishing on coral reefs: a tale of two scales. Ecol. Appl. 16, 1631-1635. doi: 10.1890/10510761(2006)016[1631:RFBFOC]2.0.CO;2

Gaines, S. D., White, C., Carr, M. H., and Palumbi, S. R. (2010). Designing marine reserve networks for both conservation and fisheries management. Proc. Natl. Acad. Sci.U.S.A. 107, 18286-18293. doi: 10.1073/pnas.0906473107

Gilmour, J. P., Smith, L. D., Heyward, A. J., Baird, A. H., and Pratchett, M. S. (2013). Recovery of an isolated coral reef system following severe disturbance. Science 340, 69-71. doi: 10.1126/science. 1232310

Graham, N. A., Wilson, S. K., Jennings, S., Polunin, N. V., Bijoux, J. P., and Robinson, J. (2006). Dynamic fragility of oceanic coral reef ecosystems. Proc. Natl. Acad. Sci. U.S.A. 103, 8425-8429. doi: 10.1073/pnas.0600693103

Green, A. L., and Bellwood, D. R. (2009). Monitoring Functional Groups of Herbivorous Reef Fishes As Indicators of Coral Reef Resilience-A Practical Guide for Coral Reef Managers in the Asia Pacific Region. IUCN Working Group on Climate Change and Coral Reefs. Gland: IUCN.

Hara, S., Duray, M. N., Parazo, M., and Taki, Y. (1986). Year-round spawning and seed production of the rabbitfish, Siganus guttatus. Aquaculture 59, 259-272. doi: 10.1016/0044-8486(86)90008-6

Hilborn, R. (2015). Marine protected areas miss the boat. Science 350:1326. doi: 10.1126/science.350.6266.1326-a 
Hirai, N., Koiso, M., Teruya, K., Kobayashi, M., Takebe, T., Sato, T., et al. (2013). "Success of seed production of humphead wrasse Cheilinus undulatus with improvement of spawning induction, feeding, and rearing conditions," in US-Japan Aquaculture Panel Symposium (Honolulu, HI), 107.

Hoey, A. S., and Bellwood, D. R. (2009). Limited functional redundancy in a high diversity system: single species dominates key ecological process on coral reefs. Ecosystems 12, 1316-1328. doi: 10.1007/s10021-009-9291-Z

Hughes, T. P., Huang, H., and Young, M. A. L. (2013). The wicked problem of China's disappearing coral reefs. Conserv. Biol. 27, 261-269. doi: 10.1111/j.15231739.2012.01957.x

Kelly, L. W., Williams, G. J., Barott, K. L., Carlson, C. A., Dinsdale, E. A., Edwards, R. A., et al. (2014). Local genomic adaptation of coral reef-associated microbiomes to gradients of natural variability and anthropogenic stressors. Proc. Natl. Acad. Sci. U.S.A. 111, 10227-10232. doi: 10.1073/pnas.1403 319111

Kuffner, I. B., Walters, L. J., Becerro, M. A., Paul, V. J., Ritson-Williams, R., and Beach, K. S. (2006). Inhibition of coral recruitment by macroalgae and cyanobacteria. Mar. Ecol. Prog. Ser. 323, 107-117. doi: 10.3354/meps323107

Lester, S. E., Halpern, B. S., Grorud-Colvert, K., Lubchenco, J., Ruttenberg, B. I., Gaines, S. D., et al. (2009). Biological effects within no-take marine reserves: a global synthesis. Mar. Ecol. Prog. Ser. 384, 33-46. doi: 10.3354/meps 08029

Lindegren, M., Möllmann, C., and Hansson, L. A. (2010). Biomanipulation: a tool in marine ecosystem management and restoration? Ecol. Appl. 20, 2237-2248. doi: 10.1890/09-0754.1

Lorenzen, K., Agnalt, A. L., Blankenship, H. L., Hines, A. H., Leber, K. M., Loneragan, N. R., et al. (2013). Evolving context and maturing science: aquaculture-based enhancement and restoration enter the marine fisheries management toolbox. Rev. Fish. Sci. 21, 213-221. doi: 10.1080/10641262.2013.837358

MacNeil, M. A., Graham, N. A., Cinner, J. E., Wilson, S. K., Williams, I. D., Maina, J., et al. (2015). Recovery potential of the world's coral reef fishes. Nature 520, 341-344. doi: 10.1038/nature 14358

MASNA (2016). Gearing Towards the Aquaculture of the Palette Surgeonfish. Available online at: http://masna.org/masna-programs/palette-surgeonfish/

McClanahan, T. R., Graham, N. A. J., MacNeil, M. A., Muthiga, N. A., Cinner, J. E., Bruggemann, J. H., et al. (2011). Critical thresholds and tangible targets for ecosystem-based management of coral reef fisheries. Proc. Natl. Acad. Sci. U.S.A. 108, 17230-17233. doi: 10.1073/pnas.1106861108

McClanahan, T. R., Marnane, M. J., Cinner, J. E., and Kiene, W. E. (2006). A comparison of marine protected areas and alternative approaches to coral-reef management. Curr. Biol. 16, 1408-1413. doi: 10.1016/j.cub.2006.05.062

McManus, J. W. (1997). Tropical marine fisheries and the future of coral reefs: a brief review with emphasis on Southeast Asia. Coral Reefs 16, S121-S127. doi: $10.1007 / \mathrm{s} 003380050248$

Mumby, P. J., and Harborne, A. R. (2010). Marine reserves enhance the recovery of corals on Caribbean reefs. PLoS ONE 5:e8657. doi: 10.1371/journal.pone. 0008657

Mumby, P. J., Hastings, A., and Edwards, H. J. (2007). Thresholds and the resilience of Caribbean coral reefs. Nature 450, 98-101. doi: 10.1038/nature06252
Mumby, P. J., and Steneck, R. S. (2008). Coral reef management and conservation in light of rapidly evolving ecological paradigms. Trends Ecol. Evol. 23, 555-556. doi: 10.1016/j.tree.2008.06.011

Newton, K., Côté, I. M., Pilling, G. M., Jennings, S., and Dulvy, N. K. (2007). Current and future sustainability of island coral reef fisheries. Curr. Biol. 17, 655-658. doi: 10.1016/j.cub.2007.02.054

Obolski, U., Hadany, L., and Abelson, A. (2016). Potential contribution of fish restocking to the recovery of deteriorated coral reefs: an alternative restoration method? Peer J. 4:e1732. doi: 10.7717/peerj.1732

Rinkevich, B. (2014). Rebuilding coral reefs: does active reef restoration lead to sustainable reefs? Curr. Opin. Environ. Sustain. 7, 28-36. doi: 10.1016/j.cosust.2013.11.018

Rogers, A., Harborne, A. R., Brown, C. J., Bozec, Y. M., Castro, C., Chollett, I., et al. (2015). Anticipative management for coral reef ecosystem services in the 21 st century. Glob. Change Biol. 21, 504-514. doi: 10.1111/gcb.12725

Russ, G. R., and Alcala, A. C. (2011). Enhanced biodiversity beyond marine reserve boundaries: the cup spillith over. Ecol. Appl. 21, 241-250. doi: 10.1890/091197.1

Vergés, A., Bennett, S., and Bellwood, D. R. (2012). Diversity among macroalgaeconsuming fishes on coral reefs: a transcontinental comparison. PLoS ONE 7:e45543. doi: 10.1371/journal.pone.0045543

Siar, S. V., Agbayani, R. F., and Valera, J. B. (1992). Acceptability of territorial use rights in fisheries: towards community-based management of smallscale fisheries in the Philippines. Fish. Res. 14, 295-304. doi: 10.1016/0165 7836(92)90038-U

Soto, D. (2009). Integrated Mariculture: A Global Review. FAO Fisheries and Aquaculture, Vol. 529. Technical Paper, 183 FAO, Rome.

Stone, R. (2007). A world without corals? Science 316, 678-681. doi: 10.1126/science.316.5825.678

Suding, K. N., Gross, K. L., and Houseman, G. R. (2004). Alternative states and positive feedbacks in restoration ecology. Trends Ecol. Evol. 19, 46-53. doi: 10.1016/j.tree.2003.10.005

White, A. T., Vogt, H. P., and Arin, T. (2000). Philippine coral reefs under threat: the economic losses caused by reef destruction. Mar. Pollut. Bull. 40, 598-605. doi: 10.1016/S0025-326X(00)00022-9

Conflict of Interest Statement: The authors declare that the research was conducted in the absence of any commercial or financial relationships that could be construed as a potential conflict of interest.

The reviewer JD and handling Editor declared their shared affiliation, and the handling Editor states that the process nevertheless met the standards of a fair and objective review.

Copyright (C) 2016 Abelson, Obolski, Regoniel and Hadany. This is an open-access article distributed under the terms of the Creative Commons Attribution License (CC $B Y)$. The use, distribution or reproduction in other forums is permitted, provided the original author(s) or licensor are credited and that the original publication in this journal is cited, in accordance with accepted academic practice. No use, distribution or reproduction is permitted which does not comply with these terms. 